Article No 233

DOI: https://doi.org/10.26881/srg.2020.7.08

Citation:

Максимович, В. (2020). Культуротворческая роль канона

в художественной системе Максима Богдановича. Studia Rossica Gedanensia, 7: 100-109.

DOI: https://doi.org/10.26881/srg.2020.7.08

Maksimovič, V. (2020). Kul'turotvorčeskaâ rol' kanona v hudožestvennoj sisteme

Maksima Bogdanoviča. Studia Rossica Gedanensia, 7: 100-109.

DOI: https://doi.org/10.26881/srg.2020.7.08

\title{
КУЛЬТУРОТВОРЧЕСКАЯ РОЛЬ КАНОНА В ХУДОЖЕСТВЕННОЙ СИСТЕМЕ МАКСИМА БОГДАНОВИЧА
}

\section{ВАЛЕРИЙ МАКСИМОВИЧ / VALERIJ MAКSIMOVICH}

Национальная академия наук Беларуси / National Academy of Sciences of Belarus Институт философии / Institute of Philosophy

Центр философии литературы и эстетики / Center for Philosophy of Literature and Aesthetics ул. Сурганова 1/2, 220072 Минск, Беларусь / Surganova st. 1/2, 220072 Minsk, Belarus

E-mail: valery.maximovich@gmail.com ORCID: https://orcid.org/0000-0002-9062-6984

(Получено / Received 17.07.2020. Принято / Accepted 27.07.2020)

\section{Abstract \\ Cultural role of canon in the artistic system of Maxim Bogdanovich}

The author of the article examines cultural role and significance of canon, defines function and significance of communicative-conversational strategies in the artistic system of Belarusian literary classic Maxim Bogdanovich. The poet cultivated the idea of a common cultural space on the basis of canonical patterns as a natural result of cultural and historical development.

Key words: creative potential, canon, artistic system, communicative-conversational strategies, cultural work 


\section{Резюме}

В статье исследуется культуротворческая роль и значение канона, определяется функция и значение коммуникативно-диалоговых стратегий в художественной системе классика белорусской литературы Максима Богдановича. Обращаясь к каноническим образцам, поэт культивировал идею о едином культурном пространстве как закономерном итоге культурно-исторического развития.

Ключевые слова: творческий потенциал, канон, художественная система, коммуникативно-диалоговые стратегии, культуротворчество

Классический канон воспринимается и трактуется прежде всего как результат культурного осознания, создающего и сохраняющего образцовые тексты. С этой точки зрения классика предстает как один из механизмов культуры, гарантирующих, с одной стороны, непрерывность традиции, с другой - постоянное возобновление стремления к совершенству, которое всякий раз достигается новыми художественными средствами. Текст приобретает статус классического, когда литературное совершенство подтверждается культурным отбором и его способностью воздействовать на духовно-культурные основы общества. В этой связи Ю. Лотман справедливо утверждает:

Каноническое искусство играет огромную роль в общей истории художественного опыта человечества. (...) ...вряд ли имеет смысл рассматривать его как некоторую низшую или пройденную стадию. И тем более существенно поставить вопрос о необходимости изучать не только его внутреннюю синтагматическую структуру, но и скрытые в нем источники информативности, позволяющие тексту, в котором все, казалось бы, заранее известно, становиться мощным регулятором и строителем человеческой личности и культуры (Лотман 1998: 441).

Следует заметить, что творчество в художественном каноне предполагает не механическое воспроизведение образца, но слепое следование эстетическим принципам и нормам, которые он в себе несет. Это происходит по той причине, что «классические произведения воплощают в самой чистой форме вневременные нормы. Поэтому они являются мерилом и мерой как для эстетического суждения, так и для художественного творчества» (Ассман 2004:118).

Классик белорусской литературы Максим Богданович (1891-1917) стал общепризнанным законодателем эстетического поэтического канона благодаря аккультурации мирового художественного и философского опыта с опорой на национальный культурный контекст. Обращение поэта к каноническим формам стиха имеет свою психологическую, культурологическую, историко-культурную обусловленность и свидетельствует о его желании художественными жанрово-стилевыми средствами воспроизвести исторический путь, пройденный эстетическим сознанием, возобновить, зафиксировать «следы», «коды», составляющие в совокупности генетическую память, «праоснову» мировых литературно-художественных памятников. Подобное обращение имело огромный культуросозидательный смысл. Это позволяло, во-первых, раскрыть, про- 
демонстрировать образно-поэтические возможности своего родного языка, его способность «работать в каноне», отвечать особым формальным требованиям; во-вторых, представить панорамное видение культурно-исторического процесса в его вершинных достижениях; в-третьих, посредством особой «системы призм» реконструировать, сфокусировать, свести в одно образцовые, высокотехничные художественные формы, виды, жанры. При этом поэт допускал возможность видоизменения канона, привнесение в него необходимых коннотаций, отступлений, признавая за ним право быть открытой традицией. Тем самым он как бы утверждал мысль, что несмотря на разительные особенности каждой социокультурной общности, различие стран и народов, эпох и цивилизаций, объективно имеет место единство, подобие в освоении людьми пространства жизненного мира посредством обращения к художественным символическим формам. Именно классические тексты сохраняют и передают культурную традицию благодаря наибольшей импликации в них кодов культуры предшествующих эпох.

Одно из значений слова «канон» - образец, так что в определенных контекстах канон и классика - синонимы. Канон предполагает верность следования не столько тексту-образцу, сколько той сути прекрасного, которую он являет. Как известно, теоретические проблемы прекрасного («красы і мастацтва») Богданович сделал предметом своего поэтического творчества. Предельно сосредоточенное внимание на художественной форме стиха стало благодатной основой для обращения к философским идеям, связанным с объяснением парадоксов прекрасного: превращение безобразного в прекрасное, прекрасного в безобразное, сущность антиномий прекрасного и этического (красоты и добра), вечного искусства и трагической миссии художника. При этом Богданович не предлагает каких-то цельно оформленых, рационалистически выверенных философских умозаключений. Наоборот, своими произведениями он ставит множество вопросов, оставаясь открытым для различных интерпретаций.

Прекрасное Багданович прежде всего связывает с формой, при этом последняя предстает как подвижное и относительное. Поэт отдает предпочтение формам стиха, которые подчиняются особому правилу - канону. Наиболее известны среди них - рондо, рондель, триолет, ритурнель, терцина, гекзаметр, сонет. Чем же прельщала поэта каноническая форма? Для ответа на этот вопрос следует обратиться к научному исследованию упомянутого нами немецкого исследователя Ассмана, который понимает под каноном «такую форму традиции, в которой она достигает высшей внутренней обязательности и крайней формальной устойчивости». При этом он подчеркивает, что канону свойственна

связь между строгостью формы и открытостью к продолжению. Это верно для всех произведений искусства, ставших образцом в своем жанре и поэтому классикой. Только через классицистическое, имитирующее обращение, через mimesis может принцип канона осуществлять свою функцию формы культурного воспоминания, как прибежище ретроспективных поисков ориентации. (...) Канонизация - это не каприз истории рецепции, а исполнение или осуществление потенции, заключенной в самом произведении благодаря строгости его формы и подчинению правилам (Ассман 2004: 115-116). 
Творческий акт в восприятии Богдановича понимался как акт сознательный, рациональный. Поэт в его представлении - не порождение счастливой случайности, а итог глубоких рефлексий, упорного и изнурительного труда. Эта идея отчетливо проступает в стихотворении Ліст да П. Ластоўскага, где поэт излагает свое видение творческого процесса, раскрывает роль в нем рациональной составляющей, реабилитирует личность известного итальянского и австрийского композитора Антонио Сальери (1750-1825), который, согласно поэтической версии Пушкина, из зависти отравил Моцарта. Богданович, напротив, опровергает это утверждение, подчеркивая удивительное трудолюбие, «холодный разум», чрезмерную сосредоточенность в процессе творчества мастера:

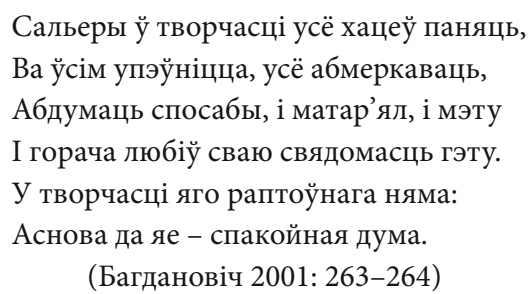

Какутверждает О. Лойко, «по существу образ Сальери в Лісте - своеобразный автопортрет Богдановича, а Лicm в целом - поэтизация размышления, „спакойнай думы” и труда - поэтического мастерства как основного, что является одним из начал поэзии Богдановича» (Лойка 1966: 104).

Признавая сознательный характер творчества, Богданович тем самым указывал и на философско-обобщенный характер своих поэтических образов и картин, на создание определенной модели, универсума значений, позволяющих, по словам Лотмана, «воспроизводить модель мира в ее самых общих очертаниях» (Лотман 1998: 30). Канон в данном случае выступает в роли универсальной культурной формы, первообразца, «кода», удерживающего и сохраняющего в себе все свойства целого, универсальную ценностную основу, способствующую нравственному и художественному освоению мира. Художественное творчество (художественное измерение) выступало для Богдановича высшим проявлением человеческого духа, стремящегося к гармонии, преемственности, к созиданию универсальной культуры, имеющей равновеликое значение для всех субъектов творчества. По существу, культивируя канонические образцы, делая генеалогический срез прежде всего европейской художественной традиции, Богданович культивировал идею о едином культурном пространстве как закономерном итоге культурно-исторического развития, в котором обнаруживается подобие, близость экзистенциально-герменевтических смыслов, истолкований, значений, делая при этом попытку посредством обращения к мировому художественному наследию выявить и зафиксировать механизм коммуникативного кодирования ценностей и смыслов культуры. Это представлялось возможным в силу того, что все значимые культурные артефакты в силу действия объективных законов имеют общие основания, общие корни, так как они созданы путем совместного культуросозидающего действия и коммуникации. В свою очередь, это открывает путь к преодолению противоречий в сфере духовного производ- 
ства, дает возможность для достижения определенного единства взглядов, подходов, устремлений в реализации эстетического идеала.

Художественные константы, которые сложились еще в период античности, в эпоху Возрождения и Просвещения, избираются Богдановичем в качестве идеального эталона, по которому он оценивает и современный ему литературный процесс. Это дает поэту возможность увидеть самые незначительные отклонения от заданного образца, тесно соотнесенного поэтом с гармонией, изяществом формы и лаконизмом содержания. И, напротив, поэт неодобрительно относится к тем художественным изыскам, к тому содержательному художественному конструкту, в котором обнаруживает себя процесс отчуждения от мира, процесс «мироутраты», связанный с утверждением монополии социальной сферы. Он все более убеждается в том, что литература за это время не стала ближе к человеку, а созданные цивилизацией технические изобретения еще более отдалили его от жизненных благ и желанной гармонии. Поэт прилагал все усилия, чтобы избежать отчуждения мира, забвения интимного отношения к бытию, окружающей его реальности. В противном случае это могло бы привести к «самоотчуждению», «бездомности», о которой уже в более позднее время говорил Мартин Хайдеггер.

Активно эксплуатируя художественные канонические формы в своем творчестве, Богданович демонстрировал на собственном опыте способность духа преодолевать время и расстояния, тем самым обретая волю подняться над чередой обстоятельств и оставаться в измерении вечного настоящего. Творческая фантазия поэта, его очевидное сознательное пристрастие к прошлому как средоточию упоительной умиротворенности, идеальной упорядоченности, соразмерности имеют, к тому же, внутреннюю, психологическую мотивацию, связанную с обстоятельствами личной жизни. Как известно, для поэта оставался реально предсказуемым финал собственной жизни по причине неизлечимой на то время болезни - открытой формы туберкулеза. Страх будущего, желание отсрочить его приближение влекло поэта назад к «успокоенности в прошлом» - с ностальгией и воспоминанием по отношению к единственной реальности, в которой он мог быть уверен, в которой он находил себе убежище от суетности бренных будней. Убедительное подтверждение тому находим в стихотворении У старым садзе, которое дает представление об особенностях авторского художественного видения и воображения, о смыслосозидающей активности его художественной мысли, стремящейся к воссозданию условной реальности, к культивированию свидетельств прошлого.

Прыгожы сад, які любіў Вато:

Між дрэў зялёных статуі паўсталі,

Вось грот, гадзіннік сонечны, а далі

Фантан... Напэўна, саду год са сто.

Стаю я, сню пра знікнуўшыя дні

I кніжку новага пісьменніка трымаю.

Яе я разгарнуў... і закрываю, 
Здзіўлёны ўкрай, што гэта не Парні

(Багдановіч 2001: 262).

Использование в тексте имен собственных и узнаваемых исторических реалий, культурных артефактов является одной из форм выражения «вторичной трансцендентальности» (Н. Худолей), когда эти артефакты из зоны внетекстовой, периферийной переходят в зону стратегических смысловых кодов, внедренных в пространство текста для усиления, удвоения, символизации (универсализации) его контекстуальных значений, соотносясь, таким образом, с планом выражения.

Думается, именно этими художественными принципами и руководствовался поэт, поставив себе цель вывести белорусскую литературу на уровень литературы мировой. Задача усложнялось тем, что он поставил грандиозную цель, связанную со своеобразным обобщением, систематизацией мирового художественного опыта, в том числе в плане утверждения поэтического канона (канонической формы) как знака высшего качества и художественного совершенства, «освящающего принципа», служащего мерилом и критерием для творчества, эстетических исканий с опорой на общеобязательность традиции. Культивируя классические формы и виды стиха (александрийский стих, гекзаметр, пентаметр, сонет, триолет, рондо, элегия и т.д.), Богданович, по существу, не только признавал их образцовый характер, служащий критерием художественности, но и принимал систему ценностей, которая ими культивировалась, с неизменной скрытой ссылкой на конкретные образцы (имена, произведения), благодаря которым были успешно воплощены эти ценности. Более того, определяющую роль поэт отводит познанию и ценностным формам духовного освоения действительности, будучи убежденным в том, что трансформация мировидения влечет за собой и изменение отношения к природе и друг к другу.

Мысль об аксиологической предзаданности канона имеет важное значение для установления его содержательно-концептуальных оснований. Резонно будет предположить, что обращение Богдановича к каноническим формам являлось не просто следованием норме, образцу, модели, а предусматривало также художественное (содержательное) выявление определенной системы «правил социальной коммуникации и смыслообразования» (Ассман 2004: 124), т.е. заключало в себе ценностную, аксиологическую характеристику. В представлении мастера слова канон не просто выступал формой подчинения чужеродным, установленным извне кодифицированным нормам или предписаниям. Скорее, он воспринимался в качестве культуро- и смыслообразовательного принципа, способствующего утверждению и развитию культурной преемственности, национальной культурной «канонической» автономии, выделению специфических дискурсов из общего контекста культуры.

Присутствие многочисленных контекстов и культурных эпох в творчестве Богдановича очевидно. Античная и национальная мифология, классические традиции мировой поэзии, новые этико-философские открытия литературы рубежа XX-XXI веков - все это (и многое другое) формировало общую мировоззренческую и эстетическую систему белорусского поэта. Можно однозначно 
утверждать, что поэзия Богдановича вся из мира культуры, она питается ее соками, дышит ее благовониями. Своеобразно трансформируя и комбинируя известные и малоизвестные мотивы, сюжеты, темы, приобщая их к потребностям собственной литературы, Богданович оставляет за собой право на субъективное восприятие и трактовку их смысла, делая едва уловимые зашифрованные указания на первоисточники. Подобными знаками-распознавателями становятся не только эпиграфы к некоторым стихам. Внутреннее сходство и смысловая близость поэзии Богдановича к темам, мотивам, наконец, идеям мировой и прежде всего, русской литературы наблюдается даже на уровне поэтики, самой формы стиха, идентичности «стилевого мышления». И в этом выразило себя не только стремление показать жизнь во всей ее многогранности и гармоничности, направить внимание на весомость, значимость и неповторимость созданных человеком эстетических ценностей. Главный смысл усилий поэта, по словам Т. Чабан, заключался в том, чтобы «раскрыть, засвидетельствовать свою индивидуальность, свое на удивление развитое чувство индивидуальности, уникальность своей судьбы, неповторимость духовного мира» (Чабан 1992: 470), «магическое ощущение причастности к мировое тайне» (Ирина Богданович). Богдановича ничто так не привлекало и не волновало, как загадка души человека и своей собственной души. Распознать ее глубинный, сокровенный смысл или хотя бы приблизиться к разгадке - было заветной мечтой поэта.

Наличие отсылок (явных и латентных), указание на первоисточники творческого акта дает основание на признание межкультурного статуса творчества Богдановича, имеющее место одновременное присутствие нескольких художественных коммуникативных систем, свидетельствующих об авторском инициировании полисемии, внутренней диалогичности создаваемых произведений, о факте закодированности в них универсальных значений и смыслов. По сути, мы имеем дело с феноменом интертекстуальности, понимаемой как форма самонасыщения литературы, как действенный способ приращения новаторства при обращении к инонациональным контекстам.

Своим творчеством Богданович, по существу, упредил многие философские концепции современности. Во многих своих стихотворениях поэт как бы предварил те философские доктрины, которые в будущем развивали представители Франкфуртской школы (Теодор Адорно, Макс Хоркхаймер, Эрих Фромм), концептуальные идеи Герберта Маркузе (Одномерный человек), теорию коммуникативного действия Юргена Хабермаса. Творческая концепция Богдановича во многом созвучна с идеей Хабермаса о культурно-исторической реальности как порождении коммуникативной деятельности индивида. Объединяющим началом и у Богдановича, и у Хабермаса выступают многообразные культурно-исторические миры, а не экономические формации. Согласно немецкому философу, главенствующую роль в любом общественном организме играют отношения взаимодействия между людьми, интеракции, удерживающие в себе ценностнонормативные представления, являясь формой духовной деятельности. Именно горизонт жизненного мира, по Хабермасу, определяет ценностную систему значений, являясь базисной основой социальной и духовной интеграции общества. Согласно и Хабермасу, и Богдановичу, именно духовные процессы выступают 
главной движущей силой общественной эволюции, а вера в разум - средством снятия социокультурных конфликтов. Во многих стихах социально-антропологического звучания (Краю мой родны! Як выкляты Богам; Кінь вечны плач свой аб старонцы!; Рушымся, брачия, хутчэй, Народ, Беларускі народ!; Нашых дзедаў душылі абшары лясой и др.) Богданович стремится перевести социальный конфликт в зону действия коммуникативной этики, призванной способствовать анализу глобальных проблем, затрагивающих не только собственно белорусскую реальность, но мировое сообщество в целом. Прибегая к «социальному эквиваленту» в стихах гражданской направленности, Богданович возлагал надежду на то, что индивид сможет не только вскрыть причины социального неравенства, но и поразмышлять о смысле своего существования. Казалось бы, явственно ангажированный мотив, благодаря художественно-философской отрефлексированности материала, приобретал форму не локального, а универсального смысложизненного конфликта, который невольно заставлял задуматься об основах существования людей друг с другом и со всем человечеством в границах единого культурного и цивилизационного пространства.

Проблему человеческого бытия классик белорусской литературы стремился перевести из плана внешнего в план внутреннего созерцания, а самого человека воспринимал в качестве объекта и субъекта мирового бытия, видел в нем носителя самоценной духовности, отличительного типа духовности. Именно поэзия становилась для него надежным инструментом для удержания вечности, способом реализации внутренней установки на гармонизацию и синхронизацию проявленного опыта посредством его избирательной трансформации (кристаллизации, десублимации) в пределах собственной автономной художественной системы. Ему была близка идея, связанная с пониманием личности как субъекта культуры, имманентно осваивающего, расширяющего и преобразующего духовно-творческим актом границы культурного, созидающего пространства по законам гармонии и красоты.

Закрепляя за творческой личностью право на творческий эксперимент, который потенциально содержит в себе инновационные признаки, Богданович тем самым, по сути, признавал за ней и право быть основоположником традиции. Задействование, использование в сфере культуротворчества инновационных техник, их активное тиражирование в многочисленных контекстах создает предпосылки того, что со временем созданный инновационный продукт войдет в живую ткань культуры, способствуя обновлению ее ценностно-смыслового ядра.

Осознание духовной сопричастности к национально значимым культурным артефактам открывает возможность представителю каждой нации идентифицировать себя в качестве субъекта особой историко-феноменологической ауры, постигнуть смыслы и ценности, значимые для субъекта, что в итоге способно существенно расширить и обогатить его внутренний мир. В этом видится и эффект практического воплощения в жизнь идеи о коллективном бессознательном, когда смысл, значение, эйфоническое звучание стиха глубоко затрагивают в первую очередь эмоционально-чувственную сферу, эмпатию, активизируют способность к сопереживанию, соучастию. На более высоком, сознательном, 
мировоззренческом уровне художественные концепты, смыслообразы затрагивают структуры миропонимания и мироотношения и формируют наиболее общие принципы социального действия. Благодаря своей трансляционной природе (способности передавать духовный аспект жизненного опыта), они приобретают качество одного из важнейших инструментов постижения мира, становятся предпосылкой успешной социализации субъекта в рамках конкретной национальной культуры. Кроме того,

постижение социальности в особой художественной/духовной форме становится условием, позволяющим активно действующему субъекту (личности) не только раскрыть социальное начало как потенциал конкретного в историко-культурном содержании субъектного состояния, но и развить его собственно человеческое содержание, воплотив его в художественной форме (Розин 2002: 42).

С течением времени благодаря смене культурных парадигм классический текст наращивает смысловую ауру: вступая в диалогические отношения с новыми контекстами, он обнаруживает новые смыслы, что позволяет ему одновременно обеспечивать единство культурной традиции и стимулировать креативный и когнитивный потенциал человека.

Несмотря на перипетии личностного и общественного плана, поэт с завидным упорством, не переставая создавал свой художественный мир согласно критериям красоты и нравственности, тем самым духовно преодолевая не устраивающий его мир. Своим творчеством он утверждал подлинный гуманизм, созидающее начало человеческого разума и природно-жизненных сил социума. Основным творческим принципом Богдановича было стремление к универсализму, космополитизм («космос культуры»), свободное использование всех мыслимых образов, мотивов и традиций мировой культуры. Художник оригинального таланта, он сумел мастерски синтезировать на национальной почве культурные достижения разных народов, поднять искусство белорусского слова к лучшим образцам мировой литературы, открыть широкие магистрали для идейно-эстетического возвышения белорусской поэзии. «Космополитизм» поэзии Богдановича - это одна из ступеней на пути постижения национального духа. Но это и важное условие постижения целостности бытия, творения подобного «образа мира» в себе, путь возвращения к себе на более высоком духовном уровне.

\section{Библиография / References}

Assman, Â. (2004). Kul'turnaâ pamât': pis'mo, pamât' o prošlom i političeskaâ identičnost' v vysokih kul'turah drevnosti. Moskva: Âzyki slavânskoj kul'tury [Ассман, Я. (2004). Культурная память: письмо, память о прочлом и политическая идентичность в высоких культурах древности. Москва: Языки славянской культуры].

Bagdanovič, M. (2001). Poǔny zbor tvoraǔ u 3 t. T. 1: Veršy, paèmy, peraklady, dasledavannì, čarnavyâ nakidy. Minsk: Belaruskaâ navuka [Багдановіч, М. (2001). Поўны збор твораў у $3 \mathrm{~m}$. Т. 1: Вершы, паэмы, пераклады, даследаванні, чарнавыя накіды. Мінск: Беларуская навука]. 
Čaban, T. (1992). Kosmas «Vânka»: Litaraturny kamentaryj da "Vânka» Maksima Bagdanoviča. V: Bagdanovič, M. Poǔny zbor tvoraǔ u 3 t. T. 1: Veršy, paèmy, peraklady, nasledavanni, čarnavyâ nakidy. Minsk: Navuka i tehnika: 463-518 [Чабан, Т. (1992). Космас «Вянка»: Літаратурны каментарый да «Вянка» Максіма Багдановіча. В: Багдановіч, М. Поўны збор твораў у $3 \mathrm{~m}$. Т. 1: Вершы, паэмы, пераклады, наследаванні, чарнавыя накіды. Мінск: Навука і тэхніка: 463-518].

Lojka, A. (1966). Maksim Bagdanovič. Mìnsk: Navuka ì tèhnika [Лойка, А. (1966). Максім Багдановіч. Мінск: Навука і тэхніка].

Lotman, Û. M. (1998). Ob iskusstve. Sankt-Peterburg: Iskusstvo-SPB [Лотман, Ю.M. (1998). Об искусстве. Санкт-Петербург: Искусство-СПБ].

Rozin, V.M. (2002). Ličnost' kak učreditel' i menedžer "sebâ» i sub"ekt kul'tury. V: Čelovek kak sub"ekt kul'tury. Moskva: Nauka: 42-92 [Розин, B.M. (2002). Личность как учредитель и менеджер «себя» и субъект культуры. В: Человек как субъект культуры. Москва: Наука: 42-92].

Competing interests: The author declares that he has no competing interests. 